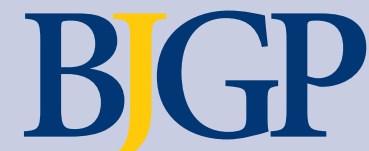

EDITOR

Roger Jones, DM, FRCP, FRCGP, FMedSci London

DEPUTY EDITOR

Alec Logan, FRCGP

Motherwell

JOURNAL MANAGER

Catharine Hull

SENIOR ASSISTANT EDITOR

Erika Niesner

ASSISTANT EDITOR

Moira Davies-Cinar

EDITORIAL ASSISTANT

Tania Marszalek

ADVERTISING EXECUTIVE

Brenda Laurent

EDITORIAL BOARD

Richard Baker, MD, FRCGP

Leicester

Stephen Barclay, MD, FRCGP, DRCOG

Cambridge

Chris Butler, MD, MRCGP

Cardiff

Kath Checkland, PhD, MRCGP

Manchester

Mark Gabbay, MD, FRCGP

Liverpool

Clare Gerada, MBE, FRCGP, MRCPsych

London

Murray Lough, MD, FRCGP

Glasgow

David Mant, MD, FRCGP, FMedSci

Oxford

Tim Peters, MSc, PhD, CStat, FFPH

Bristol

Chris Salisbury, MD, FRCGP

Bristol

John Sandars, MSc, MD, FRCGP, MRCP

Leeds

Mark Shapley, FRCGP, DCH, DRCOG

Newcastle-under-Lyme

Niroshan Siriwardena, MMedSci, PhD,

FRCGP

Lincoln

Theo Verheij, MD, PhD, MRCGP

Utrecht, The Netherlands

Sue Wilson, BA, PhD, PGA

Birmingham

2009 impact factor: $\mathbf{2 . 4 4 2}$

EDITORIAL OFFICE

14 Princes Gate, London SW7 1PU

(Tel: 0207581 3232, Fax: 0207584 6716).

E-mail: journal@rcgp.org.uk

http://www.rcgp.org.uk/bjgp

PUBLISHED BY

The Royal College of General Practitioners,

14 Princes Gate, London SW7 1PU. Registered charity number 223106. The BJGP is published by the RCGP, but has complete editorial

independence. Opinions expressed in the BJGP should not be taken to represent the policy of

the RCGP unless this is specifically stated.

No endorsement of any advertisement is implied or intended by the RCGP.

PRINTED IN GREAT BRITAIN BY

HPM Limited, Prime House, Park 2000,

Heighington Lane Business Park,

Newton Aycliffe, Co. Durham DL5 6AR.

Printed on $100 \%$ recycled paper

\title{
August Focus
}

\section{EXERCISE AND HEALTH}

Many of the papers in this month's Journal deal with major non-communicable diseases and a range of 'lifestyle' factors associated with them. The Cambridge risk score, derived from routinely collected patient data that can readily be extracted from general practice records, has been shown by Chamnan and colleagues (page 590) to perform well as a predictor of cardiovascular events. It may well find a place in practice to identify patients at elevated risk, who can then be targeted for tailored riskreduction interventions. The importance of dealing with risk factors is dramatically highlighted by Iversen and colleagues (page 563) who have conducted a further analysis of data collected in the course of the RCGP Oral Contraception Study. They conclude that, assuming causality between (as opposed to association with) lifestyle risk factors and mortality, $60 \%$ of the deaths recorded in the study could have been prevented by stopping smoking, exercising more, losing weight, and reducing alcohol intake. Inactivity and obesity were the two factors most strongly associated with mortality.

In our editorials two authors consider the extremely difficult problem of promoting exercise and, thereby, better physical and mental health. Peter Davies challenges us as individuals to learn more about giving an 'exercise prescription' and to act as role models (rather than as 'dire warnings'!) for our patients. The linked paper on childhood asthma and exercise (page 578) shows us just how complex the negotiations can be around encouraging or discouraging physical activity and how important it is for primary care teams to possess expertise in this area.

Helen Smith, reflecting on the Oral Contraception study data, extends her analysis to the problems of changing the so-called modifiable risk factors, that many regard as intractable. Echoing Davies, she also challenges us both as individuals and as a society to devise effective interventions aimed at promoting exercise and health. In an intriguing qualitative study of patients with type 2 diabetes, Peel and colleagues (page 570) confirm the imprecision of advice on exercise received from health professionals and the frequent lack of interest or encouragement with which it is delivered. They explore motivation to exercise in some detail and their finding that linking exercise to existing or planned interests and activities such as dog walking is an effective way to increase physical activity is important. It is a powerful reminder of the need to listen to patients and to negotiate management strategies that fit with their ideas and make sense in relation to their lives.

It is, of course, one thing to train and motivate health professionals and quite another to do the same for patients - notwithstanding the analogy between pay for performance in GPs' contracts and the use of financial incentives to encourage patients to lose weight or stop smoking. Health inequities and socioeconomic inequalities enter the equation. How do you encourage dog walking in areas where the streets are unsafe? How readily can poor, fragmented, and poorly supported families transform their eating habits? How can fatalism and self-neglect be replaced by a belief in a healthy, enjoyable future? There are, of course, many excellent examples of successful local and community interventions that have addressed just these problems, but they have rarely been replicated systemically. Indeed, the underlying causes of health inequalities go deep, and are hard-wired into many western societies where, in the last 10-15 years, the economic gap between the poorest and richest sectors has continued to widen, and with it inequalities in health status and life expectancy. This then raises questions about the role of society and the state in promoting the health of individuals, and thereby, the public health and leads into contentious territory. We may denigrate the 'nanny state' but still insist on a national welfare safety net. We may defend our individual freedoms to smoke and drink, but demand unconditional care from the NHS when things go wrong. At the time of writing this, a mother and father in an affluent area of London are being threatened with action by the social services if they continue to allow their children to cycle the $1.2 \mathrm{~km}$ journey to school unaccompanied. Health and safety concerns can easily become decoupled from common sense. This is a moral and political maze in which primary care - individuals and institutions - needs to take a position, that should probably be a more engaged one than simply picking up the medical pieces of social injustice.

In his recent book III Fares The Land (Allen Lane, 2010) the eminent modern historian Tony Judt examines the successes and limitations of social democracy over the last 30 years and makes a passionate plea for the reengagement of citizens with politics based on a sense of collective purpose that goes beyond the present obsession with the financial bottom line and is informed by values and aspirations rather than commercial pragmatism. The book contains a particularly persuasive chapter on the social responsibility of a state to run, and not outsource and asset strip, a rail network. The analogy with health care is unlikely to escape many readers.

\section{Roger Jones}

Editor

\section{DOI: 10.3399/bjgp10X515016}

C British Journal of General Practice 2010; 60: 553-632 